\title{
"Tudo ao mesmo tempo e agora": análise da cobertura de cotidiano no TV Folha
}

\begin{abstract}
FABiana PicCinin
Universidade de Santa Cruz do Sul (UNISC)- fabi@unisc.br Professora e Pesquisadora do Curso de Comunicação Social e do Programa de Pós Graduação Mestrado em Letras Unisc. Integrante do Grupo Interinstitucional de Pesquisa sobre Telejornalismo (GIPTele) e do Grupo de Estudos sobre Narrativas Literárias e Comunicacionais (GENALIC), ambos cadastrados no CNPQ.
\end{abstract}

\begin{abstract}
Resumo
Este trabalho segue o caminho de investigação que vem sendo traçado sobre as relações estabelecidas entre um certo padrão tecnológico e estético da sociedade contemporânea e sua incidência nas práticas e formatos do jornalismo de televisão. Parte-se da idéia de que as tecnologias digitais em combinação com as analógicas estão gerando formatos híbridos no telejornal. Por conta de um tempo caracterizado por relativizações, estas ressignificam os modelos canônicos, gerando programas jornalísticos multiformes e coberturas televisivas da mesma maneira marcadas por novas formas do dizer a partir do diálogo entre suportes. $\mathrm{O}$ artigo observa este fenômeno a partir da cobertura de cotidiano feita pelo programa TV Folha.
\end{abstract}

\section{Palavras-chave}

Televisão, múltiplos formatos, coberturas no telejornal, no impresso e na web.

\begin{abstract}
This paper follows the path of research that has been traced on the relations established between a certain standard technological and aesthetic of contemporary society and its impact on practices and formats of journalism television. It starts with the idea that digital technologies in combination with analog formats are generating hybrids on the news. On account of a time characterized by relativization, reframe these canonical models, generating multiform news programs and television coverage in the same manner marked by new forms of tell from the dialogue between brackets. The article notes this phenomenon from the coverage coti-dian taken by TV Folha program.
\end{abstract}

\section{Keywords}

Television, multiple formats, TV journal, newspaper and web coverage.

Artigo recebido em 09/05/2013 Aprovado em 08/09/2013 


\section{O padrão tecno-estético do telejornal}

A reflexão proposta neste artigo se funda na ideia de que o jornalismo de televisão - como de resto o sistema midiático - estabelece uma relação de correspondência entre suas formas de dizer com a estética e o padrão tecnológico de uma época. Dessa forma, entende-se que a discussão sobre a cobertura que faz o telejornal e as características a ela associadas exige considerar as marcas da sociedade contemporânea e como estas incidem nas suas práticas e nos seus discursos. Em razão disso, é por este caminho de investigação que se dará a reflexão - tecno-estético ${ }^{1}$ (Herscovici: 1995) - buscando compreender o telejornal em termos de operacionalidades e linguagens em suas coberturas.

Conforme propõem Benjamin (1997) e/ou MacLuhan (2002), ainda que em perspectivas diferentes, o padrão tecnológico operado em um certo tempo socialmente provoca mudanças no modo de existência das comunidades humanas, modificando seus modos de perceber e sentir, alterando suas sensibilidades. E produzindo, dessa forma, novas possibilidades de versar sobre os fatos, pautar imaginários e construir as realidades.

Neste sentido, cabe pensar especificamente que tipo de relações estabelecem as tecnologias de comunicação e informação que, a partir da segunda metade do século $\mathrm{XX}$, passam a desempenhar um lugar central na experiência dos indivíduos e, por conseguinte, nas formas como esta sociedade se narra, especialmente no que diz respeito à arquitetura do sistema midiático e nele o jornalismo de televisão. A exemplo de pesquisas anteriores (Piccinin: 2007(a); 2007 (b); 2008), as profundas e intensas mudanças advindas do cenário de imersão tecnológica em que se vive incidem na experiência contemporânea acelerando processos, virtualizando relações e estabelecendo conexões descentralizadas. Esses fenômenos acabam por ser causa e conseqüência da relativização dos conceitos de tempo e espaço que, no âmbito

\footnotetext{
${ }^{1}$ Segundo Herscovici (1995, p.123), um sistema tecno-estético se define, portanto, por um conjunto coerente de estruturas tecno-estéticas, que, através de um certo modo de funcionamento econômico, determina parcialmente uma estética. Para o autor, o sistema tecno-estético não se resume a uma variante característica de uma firma específica, mas de toda uma mídia, que é dominante (Piccinin:2007, p. 79).
} 
midiático jornalístico, vão significar, sobretudo, a sobrevalorização da instantaneidade e da força enunciativa da imagem pela sua capacidade de sintetizar o dizer num contexto de aceleração.

Por outras palavras, como lembra Castells (2002), o que se torna próprio da Sociedade em $\operatorname{Rede}^{2}$ é que, uma vez sendo as tecnologias de informação o cerne do processo de mudança, ao redor delas está associada uma série de grandes avanços tecnológicos integrantes de uma conjuntura, que reflete um determinado estágio do conhecimento, além de um ambiente institucional e industrial específico. No caso da mídia, por conta do modelo tecnológico centrado na digitalização oportunizada pela rede, esta desfruta da condição estratégica de ser ao mesmo tempo a infraestrutura por onde são distribuídos os conteúdos, bem como os próprios fluxos que circulam pelos quatro cantos do planeta. Uma dinâmica que faz o sistema midiático conquistar uma nova envergadura a ponto de se converter, por isso, num quarto bios ${ }^{3}$ regido pela midiatização que é evidenciada, conforme diz Sodré (2002) pela:

(...) tendência à "virtualização" ou telerrealização das relações humanas, presente na articulação do múltiplo funcionamento institucional e de determinadas pautas individuais de conduta com as tecnologias da comunicação. A estas se deve a multiplicação das tecnointerações setoriais (Sodré: 2002, p. 21).

No jornalismo, neste novo bios, o fenômeno da midiatização também é proposto por Soster (2012), percebendo-o em quatro movimentos: a co-referencialidade, a autoreferencialidade, a dialogia e a descentralização. Tendo a mídia ocupado a centralidade da experiência contemporânea por meio de onde tudo acontece e se dá acontecer, o jornalismo vinculado ao compromisso com a referencialidade vai operando a partir de si e para si. Ou seja, nessa ambiência de imersão tecnológica, a mídia jornalística se marca por instituir o presente e ao mesmo tempo continuamente dizer que assim o faz e, por

\footnotetext{
2 A Sociedade em Rede, segundo Castells (2002), caracteriza-se pela substituição dos valores fundamentados no uso da razão e em processos operados mecânica, linear e verticalmente, baseados em estruturas axiomáticas da Sociedade Industrial para uma nova etapa de organização societária marcada pela aceleração dos processos, fruto das conectividades tecnológicas, pela relativização e flexibilização dos conceitos e pela descentralização das operações em rede.

3 Sodré utiliza o termo quatro bios porque distingue a partir de Aristóteles três gêneros de existência (bios) na Polis: vida contemplativa, vida política, vida prazerosa. (Sodré: 2002, p. 25).
} 
isso, se auto referendando a ponto de converter até mesmo os bastidores da produção em componente estrutural da informação.

No que diz respeito à co-referência, observa-se que a instituição jornalística vale-se de seus pares para falar do jornalismo feito por si e pelos outros. Ou seja, pautas, reportagens entram numa circularidade contínua de retornos discursivos dentro do sistema midiático. Já pela descentralização, o jornalismo produzido pelas mídias contemporâneas, por operar numa condição de rizoma, rompe com a hierarquia de uma instituição midiática sobre outra, desfazendo as diferenças hegemônicas e graus de importância entre si. Por outras palavras, não se trata de falar ou se referenciar em um jornal, TV, rádio ou site, mas sim de um conjunto de mídias.

Por fim, a dialogia faz parte da tendência ao diálogo estabelecido entre as mídias e outros campos do conhecimento para dentro da arquitetura midiática ao produzir diferenças que estabeleçam diferenças. Nesse caso, pode-se dar como exemplo o movimento de busca pela estetização da notícia freqüente nos telejornais a partir principalmente do uso dos recursos virtuais via artes visuais no que diz respeito à forma, e da apropriação dos recursos da literatura com relação à composição do texto.

Com relação ao suporte onde isto se dá, vê-se que a televisão é a própria tradução per si da metamorfose em processo. Do ponto de vista da produção dos programas e dos telejornais, a mudança tecnológica resultou por hora num sistema híbrido. Sabe-se que as emissoras operam na plataforma digital, ainda que não integralmente, mantendo operações também em sistemas analógicos resultando nesta mescla em práticas e conseqüentes narrativas correspondentes. Assim, há todo tipo de situação neste sentido: das emissoras que já estão totalmente integradas digitalmente, das que operam em boa parte digitalmente, mas ainda estão em processo de adaptação aos novos parâmetros, e as que mantêm os dois sistemas, analógico e digital, funcionando, o que acaba por gerar também diferentes contextos de operação produtiva. No entanto, não cabe aqui aprofundar o âmbito da produção, posto que a atenção irá em direção à análise do conteúdo final e o que, de fato, é ofertado ao telespectador.

A esta altura, também cabe lembrar que a digitalização e entrega de sinal digital não coincidem com a digitalização enquanto conceito e possibilidades oferecidas no que 
diz respeito à linguagem. Neste trabalho, empreende-se a discussão sobre os recursos e experimentações que as tecnologias digitais possibilitam e como influenciam no fazer telejornalístico e sua incidência no resultado final. Ou seja, as hibridações e simbioses que a linguagem analógica em combinação com a digital geram em uma determinada programação a partir do condicionamento do programa analogicamente distribuído em dia e horário em uma concepção axiomática, de um ponto para vários, em convivência com as flexibilizações de horário, formato e consumo oportunizadas pela digitalização (Piccinin: 2007). O modelo analógico oferece audiência e tradição, mas não dialoga e oferece pouca interação com seus públicos. Já o modelo digital propõe reciclagens nos formatos narrativos, o rompimento com a lógica de verticalidade e horizontalização, o experimento de novas linguagens fruto dos recursos virtuais e hipertextuais, a aplicação para redes sociais e destas para a interação e participação no produto pelo receptor.

É no meio deste caminho que se põe o telejornal, programa dentro da grade da emissora comprometido com a referencialidade e vinculado à audiência, filho das tradições mais canônicas do sistema operacional de televisão, mas também necessariamente convidado a se reinventar num tempo de mutação e transformações intensas neste cenário de convergência e virtualização. Estas transformações, naturalmente, aparecem enquanto manifestação de mudança também como fruto da estética de um tempo. No que diz respeito ao telejornal, a nova ambiência que refaz práticas e formatos midiáticos encontra correspondência com um tempo marcado pelas relativizações e hibridações. Depois das convicções e verdades inabaláveis da racionalidade moderna, a experiência contemporânea traz de um lado a urgência, fruto do sentido de aceleração gerado pelas novas tecnologias e com ela a ascensão da imagem, capaz de sintetizar as epistemologias necessárias num tempo de tanta pressa (Jameson: 1997), uma vez que o "ver" possibilita o "compreender" de forma mais rápida do que em outras linguagens e formas narrativas. De outro lado, o novo cenário promove a necessidade de se rever os lugares, as dimensões de espaços e tempo e os conceitos tradicionais em todos os campos do conhecimento, inclusive e, sobretudo, no campo da cultura e da mídia e nelas do jornalismo de televisão e seus gêneros. 
Ou seja, se a Modernidade marcou a racionalidade e sua crença na capacidade de explicar o mundo, o contemporâneo assume sua insuficiência em gerar epistemologias capazes de acabar com as dúvidas, e desta condição advém as várias possibilidades em experimentação a que, em outros trabalhos se chamou de estética dos múltiplos (Piccinin: 2012). A estética dos múltiplos diz respeito justamente a um tempo traduzido pela ausência de uma marca hegemônica, em oposição à Modernidade, reconhecido em seu contrário pelas várias expressões e formatos narrativos concomitantes e atuais. Relativizados os conceitos, agora líquidos, fluidos, fugazes e vaporosos (Bauman: 2001), assumem a impossibilidade dos limites definidos e definitivos, de maneira que é neste continuum de mutação e metamorfoses que os dizeres e as práticas narrativas de modo geral, ao se apresentar no intuito de narrar este tempo - e dentro delas, sobretudo, as narrativas midiáticas/jornalísticas - vão sofrendo este atravessando conceitual e de suporte e, assim, hibridizando-se.

Como a contemporaneidade se apresenta como um terreno fértil de erosão das fronteiras entre formas e modos de narrar, o "deslizamento" e as sobreposições (Figueiredo: 2010) que parecem se manifestar tratam, justamente, desse momento em que os suportes mesclam-se, produzindo também narrativas híbridas no telejornal. $\mathrm{O}$ contemporâneo produz, portanto, um jornalismo que se desfaz e refaz por sua contínua reciclagem e construção, não fixado em uma tecnologia que lhe dê vida, mas em várias ao mesmo tempo, diluindo as fronteiras entre os conceitos narrativos praticados e tão vigorosos até a Modernidade. Mostra-se móvel, capaz de se reconfigurar e de ser convergente, nos moldes do que Jenkins (2006: p. 27) apresenta ser a convergência, entendida como (...) o fluxo de conteúdos através de múltiplos suportes midiáticos, à cooperação entre múltiplos mercados midiáticos e ao comportamento migratório dos públicos dos meios de comunicação e que, portanto, diz respeito à mobilidade física e conceitual da cobertura jornalística de televisão. 


\section{Como se tipificam as coberturas do telejornal? $O$ caso TV Folha}

O programa de notícias da grade de uma emissora é em geral condicionado tanto pelas interferências tecnológicas quanto estéticas ${ }^{4}$. A proposta é entender, neste tempo de transformações, como o tecno-estético incide nas formas de dizer e, portanto, nas coberturas contemporâneas que fazem os telejornais. Diante do cenário de hibridação apresentado, cabe pensar de que telejornal conceitualmente se está falando. Para tanto, parece oportuno se valer do conceito de gênero proposto por Machado (1999) trazido da literatura, segundo o qual, ainda que se desconstitua a categoria, é ela que orienta o uso da linguagem em determinado meio e que garante as inteligibilidades. Portanto, é a partir dela que se pode avançar na compreensão dos novos formatos que surgem, bem como na busca por sua radiografia, desde que se mantenha a vigilância na necessidade de adaptação e de flexibilidades.

O programa que se traz à análise neste artigo, o TV Folha, e nele sua proposta de cobertura da editoria de cotidiano, é fruto de uma parceira entre a TV Cultura de São Paulo e o Jornal Folha de S. Paulo. E a despeito das implicações ético-políticas desse acordo e de suas repercussões (e que aqui não se vai tratar), apresenta-se como exemplo bastante evidente do que se tem procurado discutir ao longo de algum tempo de pesquisa acadêmica no que diz respeito aos novos formatos oriundos dos sistemas híbridos de produção e entrega de conteúdo no telejornalismo.

Segundo Sérgio Dávila (2012) $)^{5}$, diretor executivo do jornal, O programa nasceu da ideia de diversificar as plataformas que publicam o conteúdo do jornal. Seu sucesso mostra que o público televisivo reconhece a qualidade do jornalismo da Folha. O TV Folha estreou em 11 de março deste ano. Desde lá vai ao ar sempre aos domingos a partir das 20h, ou seja, depois que o jornal Folha de S. Paulo já circulou há pelo menos $12 \mathrm{~h}$, e reprisa à meia-noite. Isso significa dizer que as matérias que vão ao ar na TV já

\footnotetext{
${ }^{4}$ Compreende-se que um telejornal é fruto também de interferências políticas, sociais, econômicas e culturais. Mas neste trabalho a opção metodológica resultou num recorte nestes dois aspectos: tecnológico e estético.

${ }^{5}$ Dados disponíveis na matéria da Folha On line do dia 10/06/2012. "TV Folha" completa 3 meses com furos e histórias exclusivas. $\quad$ Disponível em http://noticias.bol.uol.com.br/entretenimento/2012/06/10/quottv-folhaquot-completa-3-meses-com-furose-historias-exclusivas.jhtm
} 
foram tratadas no suporte impresso com bom tempo a ponto de estas serem consideradas velhas em termos dos padrões contemporâneos. Os 30 minutos de duração na televisão são estruturados em três blocos compostos, em cada um, de uma a duas grandes matérias que tem em média 6 minutos ${ }^{6}$.

As editorias presentes, em geral, por ordem de frequência são Política, Cultura (Ilustrada), Comportamento (Cotidiano), Esporte e Polícia. E esse conteúdo é disponibilizado, sem alterações, no site neste horário, podendo ser, portanto, assistido pela web em tempo real e ficando disponível para consulta posterior ${ }^{7}$.

Há um investimento muito grande na estetização tanto das reportagens quanto do programa em si. E esse apuro diz respeito a experimentos com as possibilidades de vídeo e de áudio na web. O programa apresenta uma vinheta com uma trilha de jazz e imagens dos próprios registros feitos durante a produção das reportagens, tanto do material que fará parte do que vai ao ar quanto de imagens de bastidores. $\mathrm{O}$ uso das imagens dos bastidores corrobora a questão da instantaneidade e da autoreferência como um valor do telejornal contemporâneo e de suas coberturas, na medida em que intenta vender a idéia de que se trabalha com o urgente e a transparência e, assim, com "menos edição possível" (Ramonet: 1999). É a mesma lógica que faz dos cenários dos telejornais no geral - e do TV Folha também - a própria redação. Integrar a redação como cenário ajuda a dizer que, diante do valor da conexão e nesta a instantaneidade, não há defasagem ou espaço entre a captação e a exibição da informação.

O telejornal utiliza também muitos recursos virtuais nas vinhetas de abertura e encerramento e nas vinhetas que marcam a editoria de cada uma das reportagens dentro do programa. Estas vinhetas têm imagens das próprias matérias seguindo a lógica de informalizar e de se autorreferir. Há uma trilha instrumental com ritmo bastante marcado que se altera com o áudio de repórteres ou entrevistados. Usa muitas cores nos efeitos virtuais aplicados ao design para web e na construção de cenários para os VTs, além de letterings que indicam a editoria e também o tema da reportagem. São

\footnotetext{
${ }^{6}$ A duração das reportagens pode variar tanto porque, em algumas temáticas, o programa pode se utilizar de vários vt's para falar do mesmo assunto. Então este tempo pode ser pensado a partir de um único VT ou de vários que falam sobre o mesmo tema, caracterizando uma cobertura.

7 Todas as reportagens dos programas exibidos até agora estão disponíveis em links individuais em http://www1.folha.uol.com.br/tv/programatvfolha/
} 
sinalizações muito evidentes do ritmo de televisão em combinação com a linguagem hipertextual. Um movimento que apresenta a dialogia estabelecida com a funcionalidade das artes visuais dentro da notícia como recurso utilizado para contar esta história, embelezando-a como é próprio do jornalismo midiatizado.

O apresentador - que é também editor - aparece, às vezes em pé e outras vezes sentado, em enquadramentos em plano médio e plano americano, sempre à esquerda do vídeo, possibilitando uma visada mais larga da redação/cenário. As cabeças são editorializadas, pretendendo oportunizar neste sentido a oferta da informação com análise e por meio das quais o apresentador institui um sentido de diálogo com os VTs. Estes em geral não tem passagem e pouco off, além de serem também intercalados pela ancoragem feita pela leitura de mais de uma cabeça sobre a mesma matéria pelo apresentador. Além disso, o repórter, quando não aparece em passagem no VT, surge na redação num lugar mais de fonte do que repórter já que privilegia a "voz" dos entrevistados e também porque traz na sua passagem as informações sobre como a matéria foi produzida. Estas estão associadas à operacionalização da mesma, privilegiando mais uma vez os bastidores, numa evidência do processo de autorreferencialidade do jornalismo midiatizado na medida em que oferece a informação e também o processo de produção da mesma. Da mesma forma, o timing acelerado das imagens - curtas neste caso - em todo telejornal dá conta desse novo tempo marcado pela influência da web.

De imediato, posto o multiformato de entrega e de apresentação do programa, poderia se fazer a pergunta conceitual: é o TV Folha um telejornal com versões impressas e online? É ele um telejornal atravessado que está tanto pelas influências do suporte impresso como da linguagem hipertextual? Examinado à luz da questão do gênero e admitindo-se que o programa trabalha com informação referencial, ou seja, cobertura das notícias gerais com algum aprofundamento, o programa estaria indexado como telejornal por atender a essas características.

No entanto, aqui também caberia o contra raciocínio, ao se dizer que ele é na verdade o jornal impresso que vai para a TV e para web, por exemplo, da mesma maneira que ocorre com os suportes jornais que disponibilizam seus conteúdos sem 
alterações (em versão pdf) nas plataformas digitais, gerando assim formatos diferentes de entrega de conteúdo. Onde começa e onde termina o produto neste sentido? O jornal impresso seria compreendido como hegemônico por ser o que cronologicamente chega primeiro ao receptor?

Também não se trata disso. Tanto porque a cronologia é insuficiente como critério para garantir isso, como porque o programa de TV é fruto de uma seleção de assuntos do que contem a Folha edição dominical impressa. Dentro desta seleção contase, portanto, uma parte do que é a Folha de S. Paulo de domingo, além do que os conteúdos são trabalhados a partir da perspectiva, dos recursos e da linguagem audiovisual, de maneira a recriar, portanto, as narrativas, permanecendo como elementos coincidentes em relação ao jornal impresso apenas o que diz respeito à pauta e aos atores envolvidos.

Assim, então se pode dizer que se trata de um telejornal? Talvez, mas não mais como o telejornal canonicamente pensado. Também a influência da linguagem web é visível não só pela possibilidade de o programa ser assistido em tempo real e depois permanecer pela semana disponível, mas por conta de essa condição influenciar a linguagem do próprio conteúdo. A estruturação do telejornal em três blocos e em cada bloco uma ou duas matérias - longas para os padrões do telejornalismo - tem a ver com o suporte web, onde este conteúdo aparece separado em três links possivelmente para que não pese muito durante a execução por conta das limitações da rede para materiais audiovisuais ${ }^{8}$.

$\mathrm{Na}$ web, ao material audiovisual são acrescidas informações em texto sobre as reportagens, ou seja, informações adicionais que não estão na plataforma televisiva, além de entrevistas disponíveis em formatos maiores que na TV. Como toda interface web, por conta dos recursos oferecidos, o telespectador é convidado a dar sua opinião e a participar do programa com sugestões e materiais, além de compartilhar o programa nas redes sociais. Poderia, dessa maneira, ser pensado como um telewebjornal na conceituação de Soster (2008), ou um telejornal online, conforme Brasil (2012),

\footnotetext{
${ }^{8}$ O conhecimento pragmático sobre a disponibilização dos conteúdos na web trata da adoção de um critério em que arquivo em áudio e vídeo disponibilizado na rede possa ter até 8 minutos para que seja possível assisti-lo sem que sua execução seja "trancada" durante o processo.
} 
caracterizado pela disponibilização dos conteúdos em áudio e vídeo na plataforma web, associados à condição de interatividade. Mas, naturalmente, por se apresentar não só pela TV e em equilíbrio de importância com o impresso e o suporte web, não pode ser considerado "só" um telejornal na web.

Diante da convergência midiática, que reúne diversos modos de entrega de conteúdo e da inter-influência da linguagem em cada um dos três suportes, o mais prudente seria pensar que o programa/produto é tudo isso ao mesmo tempo e agora, oportunizando perceber que aqui nasce um novo formato de jornal impresso, telejornal e teleweb. Ou, por outras palavras, produzindo a simbiose e a hibridação das narrativas jornalísticas, conforme tem se refletido neste artigo e marcando-se, portanto, como uma manifestação midiática jornalística típica da contemporaneidade, do jornalismo midiatizado que se descentraliza, diluindo hierarquias entre mídias, e que sem limite definido e definitivo, reinventa-se originando novos formatos.

Também é importante considerar que as plataformas se co-referenciam como um sintoma do fenômeno da midiatização. Tanto o jornal impresso convida para o programa na TV, como a TV lembra a todos que o programa pode ser assistido em tempo real pela internet, e consultado posteriormente com a possibilidade de acesso a informações complementares sobre as matérias. E na web também está, por sua vez, o convite para que se assista o conteúdo nos dispositivos móveis. Além disso, o programa de TV, ao final, faz a chamada para as manchetes de capa da edição impressa do outro dia, neste caso, da segunda-feira ${ }^{9}$.

\section{Entendendo a cobertura no TV Folha: análise de caso}

Para analisar a cobertura feita pelo programa na editoria de cotidiano considerase neste trabalho um conceito de cobertura para TV proposto por Emerim e Brasil (2011) que, ao tipificarem as mesmas, propõem como cobertura aquela feita para todo trabalho de reportagem que apresenta um tema sob diferentes abordagens, ou seja, que

\footnotetext{
${ }^{9}$ Não é objeto da pesquisa, mas é preciso referenciar que a Folha.com também faz parte do processo de autoreferência e correferência do jornalismo nos moldes propostos por Soster (2012) por conta de que também na plataforma on line do jornal há a "propaganda" do TV Folha tanto na TV quanto na web.
} 
aprofunde, desenvolva ou diversifique o tema central (2011, p. 4). E dentro deste conceito, apresentam tipificações de coberturas dentro dos programas de telejornalismo. No caso da cobertura de cotidiano do TV Folha, esta ficou identificada como a constituída de reportagens que podem (...) ocupar um bloco ou mais do telejornal pautando o tema sob diversos aspectos através de reportagens previamente produzidas. (Emerim e Brasil: 2012, p. 7).

No que diz respeito à cobertura da invasão dos sem teto ${ }^{10} \mathrm{em}$ um prédio em São Paulo, escolhida para análise neste artigo, esta foi ao ar no dia 20/05/2003 pela TV Cultura, bem como fez parte da edição impressa do veículo, foi reproduzida no ambiente web e está ainda disponível no site que congrega todo conteúdo já exibido ${ }^{11}$. $\mathrm{O}$ assunto foi tratado em duas grandes reportagens em áudio e vídeo para televisão, que na web se constituíram do segundo dos três blocos em que ficam distribuídos os conteúdos, em associação a textos que contextualizam a temática, já que na internet não há a presença do apresentador.

Na primeira matéria, o VT de 6'08" apresenta seis sonoras ${ }^{12}$. Todas as sonoras estão intercaladas em suas falas com imagens cotidianas do prédio como moradoras em atividades domésticas, crianças caminhando pelos corredores escuros, mães que carregam seus filhos, corredores antigos contrastando com corredores pintados recentemente mais iluminados, imagens com sons eventuais do show dos Racionais MC's no pátio do prédio. As sonoras dos entrevistados são utilizadas em trechos curtos e várias vezes cada uma durante o VT. Suas falas são alternadas com imagens dos

\footnotetext{
${ }^{10}$ Os picos de audiência do programa até agora se deram durante o período de 6 e 20 de maio, quando mostrou gravações exclusivas da Polícia Federal sobre o caso Cachoeira e uma participação de Mano Brown, do Racionais MC's, numa reportagem sobre o prédio invadido por 1300 famílias sem-teto. A audiência na TV foi de um ponto, o que significa 60 mil famílias na Grande São Paulo. No absoluto, a audiência do programa é baixa, no entanto, na comparação, o programa que tem três meses de vida, já tem a mesma audiência que outros tradicionais da casa como o Jornal da Cultura. Na web, não há registros da audiência, no caso de acessos, nem em tempo real e nem dos acessos posteriores. Dados disponíveis na matéria da Folha On line do dia 10/06/2012. "TV Folha" completa 3 meses com furos e histórias exclusivas. Disponível em http://noticias.bol.uol.com.br/entretenimento/2012/06/10/quottvfolhaquot-completa-3-meses-com-furos-e-historias-exclusivas.jhtm

${ }^{11 !} \mathrm{http}: / / \mathrm{www}$ 1.folha.uol.com.br/tv/programatvfolha/

${ }^{12}$ Foram entrevistados para o primeiro VT: a diretora do documentário que está sendo produzido sobre a invasão, a coordenadora do Movimento do Sem Teto do Centro, a advogada do Movimento do Sem Teto do Centro, o rapper Mano Brown que fez show no prédio, o advogado dos proprietários e o coordenador do projeto vida nova (política habitacional do município).
} 
próprios entrevistados, pela voz em off e por imagens do prédio. Seus enquadramentos sempre bem fechados no rosto são muito oportunos também para a disponibilização do conteúdo na web (Soster: 2008), (Brasil: 2012).

Além disso, os entrevistados estão em situação de muita informalidade (com exceção de um deles que aparece de terno e gravata), reiterando a busca pela transparência (autorreferência) e pelo sentido de redução da edição e tratamento da notícia. Essa é a razão pela qual o off parece ser desprezado. Este formato "organiza" por demais as informações em termos de redação e locução, formalizando a reportagem. No decorrer da matéria também presenciam-se as várias linguagens. As imagens curtas, mas com apuro estético em termos de composição de fotografia, evidenciando a visada sempre em perspectiva, remetem tanto ao ritmo de web pela duração, quanto ao cinema por sua beleza e subjetividade (Jameson: 1997). Vários letterings são utilizados sobre as imagens dando conta do título da matéria, de informações adicionais como o histórico da ocupação em datas, a localização geográfica do prédio em gráfico e a expressão "Outro lado", quando da entrevista do advogado dos proprietários, apontando para a entrega de informação em áudio, vídeo e também texto. A idéia de sintetizar conceitos nesses letterings sugere uma referência aos links usados na internet.

Na segunda matéria sobre o mesmo assunto, a estrutura de ausência de off e de passagem se repete e o investimento neste segundo momento está na entrevista de 5'56" com Mano Brown. Os trechos da sonora, sempre curtos, são intercalados com imagens em preto e branco e em cores do prédio, do show e do próprio rapper. Estas sempre em preto e branco e em dois enquadramentos que também se alternam, mas que privilegiam o rosto dele. Quanto ao áudio, este também se intercala entre a voz de Mano Brown, sua voz no show e a música "Marighella" do grupo. Também são utilizadas imagens de pontos conhecidos de São Paulo e de situações de grande confluência de pessoas para ajudar a tratar sobre as diferenças e falta de infraestrutura que a cidade pode significar para quem é pobre e/ou morador da periferia. Da mesma maneira, os letterings são usados com freqüência, ajudando a contar e nomear os depoimentos de Brown, editorializando o conteúdo. No suporte web, a entrevista com Mano Brown está, além do vídeo, também em texto. 
O fato de serem duas matérias sobre o tema e estas terem duração de 6 minutos longas para o padrão TV - e vários entrevistados, confirma a idéia de cobertura do fato, como bem pontuam Emerim e Brasil (2011). Nestes dois exemplos que tratam da mesma temática, vê-se que na forma de tratar a informação há um investimento na estetização da notícia, com buscas a licenças artísticas na composição de cena, na editorialização da própria matéria e da entrevista. São marcas que acabam por ratificar a linguagem adotada pelo programa e pela ideia que se quis até então provar, do interrelacionamento entre linguagens e seus suportes, das mídias com a arte (dialogia) e da consequente produção de narrativas outras, frutos desta mescla estética e tecnológica. Percebe-se que esse desmembramento da temática em duas grandes reportagens, e nestas o aprofundamento com vários olhares, constitui um exemplo do que se entende conceitualmente por cobertura e que, de fato, é formato freqüente no TV Folha.

Também é possível identificar que os três suportes - impresso, TV e web trabalham pela oferta de conteúdo de forma equitativa e sem hierarquia, evidenciando a descentralização já referida. E que as linguagens dos mesmos incidem em todos produzindo a mescla, neste caso em cada um dos suportes, mais especialmente na TV, por ser aqui objeto de estudo particular. E por conta disso, a análise permite dizer que esta cobertura integra um telejornal de experimentação de linguagens e que, sobretudo, por conta de os suportes se co-referenciarem continuamente, estes conteúdos precisam ser vistos em sua integralidade, para além do jornal da TV. Esse olhar é que torna possível fazer a leitura conceitual de si com toda a revisão e flexibilização que se exige neste tempo de mutações e formatos originais. Ou seja, o produto é e precisa ser visto como um todo e um tudo. Tudo ao mesmo tempo e agora. E o telejornal, ainda que considerado como parte, ressignifica-se também no todo. 


\section{Referências bibliográficas}

BAUMAN, Zygmunt. Modernidade líquida. Rio de Janeiro: Jorge Zahar, 2001.

BENJAMIN, Walter. A obra de arte na época da reprodutibilidade técnica. In: LIMA, Luiz Costa (org.). Teoria da Cultura de Massa. 4. ed. São Paulo: Paz e Terra, 1990.

BRASIL, Antonio. Sobre telewebjornalismo. Entrevista por email. Julho de 2012.

CASTELLS, Manuel. A Sociedade em Rede. 7. ed., v. 1. São Paulo: Paz e Terra, 2003.

EMERIM, Cárlida \& BRASIL, Antonio. Coberturas em telejornalismo. In: INTERCOM. Sociedade Brasileira de Estudos Intersdisciplinares da Comunicação. Recife: Pernambuco, 2011. Disponível em http://www.intercom.org.br/papers/nacionais/2011/resumos/R6-1276-1.pdf. Acesso em julho de 2012.

FECHINE, Yvana. Tendências, usos e efeitos da transmissão direta no telejornal. In: DUARTE, Elizabeth Bastos; CASTRO, Maria Lília Dias de. Televisão. Entre o mercado e a academia. Porto Alegre: Sulina, 2006.

FIGUEIREDO, Vera Lúcia Follain de. Narrativas migrantes: literatura, roteiro e cinema. Rio de Janeiro: Ed.PUC-Rio, 2010. 287 p.

HERSCOVICI, Alain. Economia da Cultura e da Comunicação. Vitória: Fundação Ceciliano Abel de Almeida, 1995.

JAMESON, Frederic. Pós-modernismo. A lógica cultural do capitalismo tardio. 2. ed. São Paulo: Ática, 1997.

MACHADO, Arlindo. "Pode-se falar em gêneros televisuais?". Famecos. No 10, junho de 1999, Porto Alegre, PUCRS/FAMECOS, p. 142-143. Disponível em http://revistaseletronicas.pucrs.br/ojs/index.php/revistafamecos/article/view/3037. Acesso em julho de 2012.

MCLUHAN, Marshal. Os meios de comunicação como extensão do homem. 12. ed. São Paulo: Cultrix, 2002.

PICCININ, Fabiana. Real porque é "ao vivo": a tecnologia no lugar da notícia no telejornal. In: FELIPPI, Ângela; PICCININ, Fabiana; SOSTER, Demétrio de Azeredo (orgs.). Metamorfoses jornalísticas. Santa Cruz do Sul: Edunisc, 2007(a).

PONTIFÍCIA UNIVERSIDADE CATÓLICA DO RIO GRANDE DO SUL Programa de PósGraduação em Comunicação Social. "Veja a Seguir": a transição do telejornal entre a linha de montagem e a rede. 2007. 241 f. Tese (Doutorado) - Pontifícia Universidade Católica do Rio Grande do Sul, 2007 (b)

Edição na Tv: Olhares híbridos no tratamento da notícia. In: FELIPPI, Ângela; PICCININ, Fabiana; SOSTER, Demétrio de Azeredo (orgs.). Edição de imagens em jornalismo. Santa Cruz do Sul: Edunisc, 2008.

. Narrativas de choque. In: GAI, Eunice Piazza \& OLIVEIRA, Vera Lúcia (orgs.). Narrativas brasileiras contemporâneas em foco. Santa Maria: Edufsm, 2012. 180 p.

RAMONET, Ignácio. A tirania da comunicação. Petrópolis: Vozes, 1999.

SODRÉ, Muniz. Antropológica do espelho. 2. ed. Petrópolis: Vozes, 2006.

SOSTER, Demétrio de Azeredo. Sistemas, complexidades e dialogias: narrativas jornalísticas reconfiguradas. In: Narrativas Midiáticas Complexificadas. PICCININ, Fabiana \& SOSTER, Demétrio de Azeredo. Santa Cruz do Sul; Edunisc, 2012.

. Telewebjornalismo, entre autonomia e o outsourcing. In: FELIPPI, Ângela, PICCININ, Fabiana \& SOSTER, Demétrio de Azeredo. Edição de imagens em Jornalismo. Santa Cruz do Sul: Edunisc, 2008.

Este artigo e todo o conteúdo da Estudos em Jornalismo e Mídia

estão disponíveis em http://www.periodicos.ufsc.br/index.php/jornalismo/index

Estudos em Jornalismo e Mídia está sob a Licença Creative Commons 